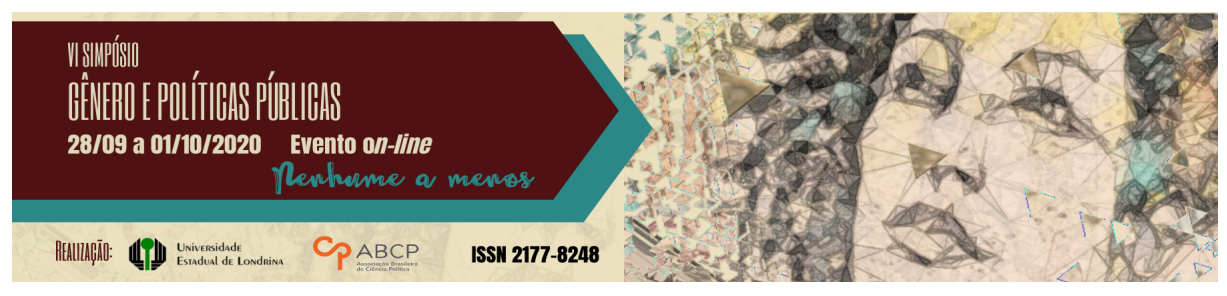

\title{
Queermuseu e o desvio necessário para pensarmos em uma nova política de representação
}

\author{
Girlainy Maia Xavier
}

\section{Resumo}

Neste trabalho é realizado um levantamento dos marcos que se perpassaram durante a exposição "Queermuseu: cartografias da diferença na arte brasileira", duramente censurada por grupos políticos e religiosos. A partir de um pensamento queer proposto pela mesma, em seu formato curatorial, são levantadas questões sobre as políticas de representação e a possibilidade de repensá-las através de um desvio às normas já estabelecidas pelas instituições, tendo em vista o caráter colonizador presente nelas, afiliados ao eurocentrismo, que tendem a responder de forma excludente, a fim de trazer para o debate novos olhares e a inclusão democrática de grupos minoritários excluídos nesses âmbitos.

Palavras-chave: queermuseu; instituições; representação.

\section{Queermuseum and the necessary deviation to think about a new representation policy}

\begin{abstract}
The aim of this work is to survey the events and milestones that took place in the exhibition "Queermuseu: cartographies of difference in Brazilian", harshly censored by political and religious groups. From a queer reflection proposed in the exhibition, in its curatorial format, there unfolds questions regarding politics of representation and the possibility of rethinking them through a detour from the norms already settled by institutions, given the colonizing character of the latter, affiliated with eurocentrism, and that tend torespond in an excluding way. Thus, the objective is to discuss new horizons and focus on the democratic inclusion of minority groups.
\end{abstract}

GT 05 - Gênero, corpo e sexualidade 
Keywords: Queermuseum, instutions, representation.

\section{Introdução}

A academia e os museus foram consolidados em princípios construídos historicamente baseados em uma lógica patriarcal das instituições, em um perfil da heteronormatividade, e nas normas sociais que a regem, refletindo na formação do cânone artístico da arte ocidental, afiliadas ao eurocentrismo. O que dificulta que novos modelos sejam inseridos de forma que venha a desconstruir estes padrões já estabelecidos. No entanto, projetos radicais representam o desvio a este padrão, como estratégia necessária para quebrarmos os modelos curatoriais tradicionais, e que transcendamos este raciocínio. A fim de incluir, de forma democrática, visões, debates, perspectivas e novas realidades, promovendo a visibilidade da produção das chamadas minorias, ou seja, uma abertura para outras narrativas (GUADÊNCIO, 2018).

A "Queermuseu: cartografias da diferença na arte brasileira" se colocou como um desses projetos, uma exposição que busca confrontar e desafiar os modelos tradicionais de curadoria, que teve como propósito oportunizar o diálogo e o debate sobre a diversidade na arte brasileira e na cultura contemporânea, através das inúmeras questões de gênero que ultrapassam os aspectos desta contemporaneidade, possibilitando que experiencemos os diversos paralelos da arte, se alinhando à perspectiva artística de outras grandes mostras, como Hide/Seek: Difference and Desire in American Portraiture (2010), realizada pela National Portrait Gallery da Smithsonian, em Washington; Ars Homo Erotica (2010), do Museu Nacional da Polônia, em Varsóvia; e a Queer British Art (2017), na Tate Britain, em Londres. Queermuseu é um museu desviante, provisional, em que se configura além dos parâmetros restritivos, excludentes e discricionários do cânone artístico e como ele é estabelecido pela academia e pelo museu.

A exposição que tinha como idealizador o curador Gaudêncio 
Fidelis ${ }^{2}$, reuniu 264 obras de 85 artistas, obras pertencentes ao quadro histórico da arte brasileira ao lado de obras da atualidade, provindas de coleções públicas e privadas, nas mais diversas linguagens artísticas. A mostra foi exposta pela Santander Cultural na cidade de Porto Alegre, tendo sua abertura dia 15 de agosto, com duração prevista para até dia 08 de outubro de 2017. Para a escolha das obras, levaram-se em conta os aspectos artísticos, culturais e históricos do objeto. O curador da exposição, adotou um mecanismo de justaposição das obras, em que as mesmas se confrontassem em períodos diversos, abolindo a cronologia. Com isso, ao invés de um "túnel do tempo", a justaposição das obras proporcionou ao expectador a importância da elucidação histórica para a compreensão do contemporâneo e para a realidade do indivíduo. No entanto, a mostra passou por diversas acusações, das quais se direcionavam principalmente a algumas obras específicas, e de forma descontextualizadas foram associadas a comportamentos sexualmente criminosos, disseminando esta visão de forma única e autoritária, o que resultou em protestos que levou ao encerramento antecipado da exposição, gerando um debate em torno da liberdade de expressão e aceitação da diversidade.

Desde o início do século XXI há um processo de emergência de novas representações identitárias de gênero nas manifestações artísticas e culturais que vem se intensificando. Nos últimos 10 anos entraram em cena debates e diálogos sobre temas antes não incluídos em pauta, como os levantados pela Queermuseu, não por sua inexistência, mas sim por uma falta de interesse e empatia aos temas. Todavia, há na sociedade contemporânea um anseio à inclusão da diversidade e o reconhecimento das diferenças de sujeitos e identidades até então invisibilizados, sub-representados ou estereotipados como manifestação da vida democrática, seja nas arenas políticas, sociais e culturais.

Como extensão dessa problemática, tenho como objetivo (i) abordar sobre a teoria queer e o significado do termo queer, (ii) realizar um levantamento dos marcos que se perpassaram durante a 
exposição "Queermuseu: cartografias da diferença na arte brasileira" para além do debate levantado por ela, (iii) discutir o conceito de representação política moderna para analisar quais obstáculos presentes e as possíveis soluções para pensarmos em políticas mais representativas e inclusivas de grupos que fogem à norma em um país dito democrático. Contudo, tendo como referencial a mostra, seus objetivos e o debate levantado através dela, no presente trabalho, busca-se compreender e relacionar a importância de levar a ideia desse museu desviante para outras esferas, de forma a constituir uma fuga antinormativa a fim de trazer para o debate novos olhares e a inclusão democrática de minorias que são excluídas do padrão institucional já estabelecido no país.

Em termos metodológicos, o presente artigo se configura numa abordagem qualitativa de caráter documental. Fundamentada em uma revisão bibliográfica, que buscou o entendimento da configuração de representação no Brasil através do entendimento do universo Queer. O instrumento de coleta de dados consistiu, além da revisão bibliográfica, informações coletadas diretamente do grupo virtual oficial de discussão da exposição no whatsapp, grupo criado pelo curador da exposição com a presença dos artistas da mesma; ademais em uma análise de discursos, e de textos jornalísticos em sites, revistas e jornais on- line e, a consulta de documentos legais, tais como, leis, pareceres, memorandos e regulamentos. A fim de compreender a relação em que ambos mantêm na atual conjuntura política, observáveis a partir da mostra Queermuseu: cartografias da diferença na arte brasileira.

\section{Teoria queer}

Na década de 1970, movimentos gays e lésbicos dominantes eram marcados pela busca, a aceitação e a integração dos homossexuais no sistema social, enfaticamente nas instituições e na conquista de marcos legais igualitários e de antidiscriminação. No 
entanto, possuía poucas ações que promovessem o respeito às diferenças de gênero, procurando encaixar todas as pessoas nãoheterossexuais e não cisgêneras em umas das identidades da sigla LGBT, dificultando a emergência das demandas de outras identidades, considerando a adesão de uma heteronormatividade para conquistar direitos, a partir de uma construção de identidade gay "positiva", que logo se opõe a uma identidade "negativa", associadas a gays afeminados, lésbicas masculinizadas, transexuais e travestis. Para muitos, as campanhas destes movimentos políticos estavam marcadas pelos valores que brancos de classe média adotavam, sem questionar ideais convencionais, repetindo privilégios e comportamentos heteronormativos, sendo assim, uma política de identidade excludente que mantinha a condição de outros grupos marginalizada. Com isso, se colocava em xeque a concepção da identidade homossexual unificada que vinha se constituindo na base de tal política de identidade (LOURO, 2001). Mas, apesar da crise na política de identidade de gênero, no início dos anos 80, com o surgimento da Aids, multiplicam-se os movimentos, devido a latente homofobia na sociedade, intensificando a discriminação já demonstrada por certos setores sociais. A intolerância, o desprezo e a exclusão fizeram com que se criassem alianças baseadas num sentimento de afinidade. A nova dinâmica dos movimentos sexuais e de gênero provocaram mudanças nas teorias, ascendendo a política queer que adotava uma postura de não assimilação

O termo queer é uma apropriação da palavra de origem inglesa que em sua definição, designa-se a algo ou alguém estranho, peculiar, excêntrico, oblíquo, diferente, bizarro. De forma depreciativa era utilizada para ofender pessoas que não seguiam o modelo padrão de sociedade e comportamento, tendo uma alusão não somente ao gênero, mas sim a grupos minoritários de forma geral. Tendo seu uso generalizado no início do século XX, usado dominantemente de forma pejorativa para mulheres e homens não heterossexuais e/ou afeminados. No entanto, a construção positiva do seu significado, que 
ainda se encontra em constante elaboração, se fez em um contexto das lutas dos movimentos pautados pelas políticas de identidade, tais como os movimentos feministas, lésbicos e gays nos Estados Unidos da América, passando por um processo de ressignificação, que logo abriu espaço para categorias mais amplas agregando grupos adjacentes, sendo uma ferramenta para problematização de algo universal por representar uma multiplicidade de ideias (ROCHA, 2014).

Apesar de não podermos apontar um ponto de partida único de seus estudos, a teoria queer começou a se consolidar a partir dos Estudos Culturais norte-americanos, no fim da década de 1980, através de um encontro entre correntes da filosofia e estudos culturais pósestruturalismo francês. Ainda que seu surgimento tenha se dado em departamentos não associados às investigações sociais, a teoria queer contrapôs estudos sociológicos sobre políticas identitárias, ganhando notoriedade ao questionar concepções clássicas sobre sujeito e identidade. Para além deste questionamento, levantaram-se discussões em relação à estrutura da sociedade heteronormativa já instalada, que resulta em uma realidade social de grupos minoritários excluídos (MISKOLCI, 2009). Ou seja, de acordo com Daniel Lourenço (2017, p. 878) sua emergência na academia enquanto novo projeto intelectual consolida-se como palavra de ordem de um novo campo de possibilidades identitárias e políticas.

Teóricos encontraram em obras como a de Michel Foucault, História da Sexualidade I: A vontade de saber (1976), conceitos mais concretos do que era apresentado pelas ciências sociais e suas hipóteses repressivas, que acabavam por naturalizar as normas heterossexuais na década de 1970. Michel Foucault, pensador francês que problematizou o discurso, o saber e o poder, associou a sexualidade à biopolítica, argumentando que o desejo era estabelecido por um modelo heteronormativo construído para padronizar as relações sexuais, e por meio de um panorama religioso e dos saberes científicos do século XIX a acusar as anomalias e os desviantes. Apesar 
de não descartar a dimensão biológica que constitui os sujeitos, considera a "natureza" da sexualidade diante da experiência humana construída, posicionada e marcada por um conjunto de capturas sociais das subjetividades, seja através de proposições morais, práticas sociais e a incitação ao discurso.

Estudos queer e o pensamento foucaultiano criaram novas ferramentas teórico- políticas que se expandiram com o modelo psicanalítico de identidade descentrada e instável. Judith Butler ampliou o argumento foucaultiano de que a sexualidade é produzida no discurso, incluindo o gênero como efeito performativo, ganhando densidade com a quebra de estruturas conceituais pautadas no binarismo.

Ainda que teóricos desse campo constituam um agrupamento diverso e muitas vezes divergente, estes mantêm compromisso com a fundamentação teórica e baseiam-se no uso da desconstrução como método de crítica e intervenção social (ROCHA, 2014). Todavia, a teoria queer surge com intuito de questionar o que entendemos como verdade em relação ao gênero; problematizar e compreender a sexualidade como construção social e histórica; se pondo a criticar discursos hegemônicos da cultura ocidental, em que o modelo heterossexual é visto como o único e correto; criticar as noções de uma essência binária e seus marcadores biológicos, desafiando as fronteiras tradicionais de gênero e sexuais, pondo em xeque as dicotomias masculino/feminino, heterossexual/homossexual, entre outras. Logo uma provocação à normatividade, devido à oposição de projetos liberais, crítica às lógicas sociais dominantes heteronormativas e negação de uma ordem que inclui uns sujeitos e exclui outros (LOURENÇO, 2017). Sendo a oposição ao binarismo e a recusa de um sujeito a desconstrução defendida pela teoria queer, pois este binarismo reforça todo ato de significação, como em um jogo entre presença e ausência para definir algo (MISKOLCI, 2009).

Ou seja, ser queer é pensar na ambiguidade, na multiplicidade das identidades sexuais e de gênero, mas, além disso, sugere novas 
formas de pensar, através de ações imperativas de afirmação, de resistência e de transformação interseccional que reflitam nas artes, nas culturas, nas mídias e, consequentemente, na política e a na sociedade.

\section{Queermuseu}

Uma das primeiras exposições com uma abordagem exclusivamente queer realizada no Brasil, a exposição "Queermuseu: cartografias da diferença na arte brasileira" reuniu 264 obras de 85 artistas, provindo de coleções públicas e privadas. A mesma explora a expressão e identidade de gênero, diversidade estética, geográfica e geracional da arte brasileira que percorrem um amplo arco histórico de meados do século $X X$ até a atualidade, cobrindo as mais diversas linguagens artísticas. E busca produzir um engajamento em torno de questões como estas a partir de uma perspectiva de diversidade e diferença utilizando-se de uma inteligência estratégica queer. E o fato de ser considerada a primeira no Brasil e na América Latina com esse perfil se dá, pois apesar de terem sido realizadas diversas exposições com questões LGBTQI+, nenhuma se intitulou ou se designou como tal. É válido ressaltar que a Queermuseu se insere na história dessas exposições não apenas por ter sido censurada, mas sim pelo seu potencial artístico.

O curador, Gaudêncio Fidelis (2018), defende a mostra construída através da ideia de um museu ficcional, provisório, metafórico e desviante. Com caráter inclusivo, o objetivo é "produzir conhecimento avançado sobre a produção artística a partir do desvio da norma canônica" (FIDELIS, 2018, p.11) articulando-se fora desses parâmetros, de forma a possibilitar o questionamento e a transgressão dessa norma, ainda que determinante.

narrativas construídas a partir de visões dominantes do cânone artístico são em grande parte artificiais, no sentido de que não respondem à atualidade e à 
diversidade da produção contemporânea em suas características mais abrangentes. Da mesma forma, a diferença é pouco levada em consideração nos termos em que a forma é aceita dentro dos patamares de interpretação e legibilidade, os quais ainda são, em grande parte, obsoletos no que se refere aos avanços da linguagem artística. ${ }^{3}$

Sua articulação constrói a possibilidade de reflexão e o deslocamento do pensamento desse centro heteronormativo. $\mathrm{O}$ museu desviante proposto pela Queermuseu se estruturou originalmente em um "choque de imagens", através de uma justaposição de obras em que as mesmas se confrontassem em períodos diversos, abolindo a cronologia e, ao invés de um "túnel do tempo", a justaposição das obras proporcionou ao expectador a importância da elucidação histórica para a compreensão do contemporâneo e para a realidade do indivíduo, instituindo uma descolonização da forma artística mediante uma perspectiva descolonizada do corpo, da cultura e das subjetividades.

O desvio é sempre a possibilidade de um encontro com outro do qual o nosso corpo, muitas vezes trêmulo e titubeante, aproxima-se quando de si mesmo se afasta. Esse horizonte de medidas, por meio do qual essa entidade corporal se movimenta em direção ao outro, percorre o caminho desviante, não um atalho, nem um caminho errado. O desvio é a forma desse caminho paralelo ao raciocínio constituído e institucionalizado. ${ }^{4}$

O desvio se constitui como uma fuga antinormativa, de maneira a possibilitar uma transversalidade discursiva, intervindo mais eficientemente nos debates públicos. A mostra é, portanto, um espaço que propõe esse desvio, sendo amplo e de diálogos irrestritos, onde se projetam suas crenças, experiências, preconceitos e medos, propondo um diálogo indispensável em momentos de retrocessos. Ou seja, a Queermuseu não se trata apenas de uma exposição queer pelo tema que abordava, mas também, de forma mais ampla e extensa do termo, através de uma perspectiva queer de se constituir, incidindo 
sobre o centro da heteronormatividade. Mas, apesar da exposição ter como propósito oportunizar o diálogo e o debate sobre as diferenças na arte brasileira, foi exatamente a intolerância com o que é diferente que levou ao encerramento antecipado da exposição e à autoritária interrupção desse diálogo.

De forma reducionista, blogueiros de extrema direita ingressaram na exposição produzindo vídeos e fotografias. Em um universo de 264 obras, generalizaram a exposição baseados em 5 obras específicas, construindo uma narrativa difamatória de forte caráter moralista sobre a exposição, acusando obras de artistas como Lígia Clark, Adriana Varejão, Bia Leite, Fernando Baril e Antonio Obá, de incitarem pedofilia, zoofilia e ataques a símbolos religiosos, que acarretou em uma onda subsequentes de ataques de larga escala em todo território nacional e internacional.

Grupos liberais e ultraconservadores se manifestaram, utilizando a ajuda e uso de bots 5 em Redes Sociais de Internet (RSIs) manipulação de algoritmos e posts pagos - com o propósito de expandir e difundir esta narrativa. E como o facebook tem restrições a alguns conteúdos publicados, o whatsapp e o twitter foram as outras plataforma utilizadas para que estes grupos se mobilizassem, sendo que no whatsapp a mobilização começou previamente, onde membros enviaram mensagens e matérias sobre a exposição às células do movimento em todo o país. Ação esta que obteve sucesso, principalmente no imaginário de uma parcela da população que não teve acesso à exposição, pois devido a um falso volume de opiniões, pessoas reais passaram a compartilhar o conteúdo, ou seja, apesar de ser gerado artificialmente por máquinas o efeito se mostrou real, impossibilitando a população de ter acesso à exposição devido ao seu encerramento antecipado.

Um dia antes da decisão de encerramento da exposição, o MBL compartilhou em sua página uma matéria do Jornalivre, utilizando-a como fonte para questionar o financiamento público da exposição. No entanto, o Jornalivre é um site-fantasma, registrado fora do Brasil, e não 
apresenta em sua interface indicação de seus administradores, nem suas matérias são assinadas. As matérias veiculadas por esse site são compartilhadas como se fossem conteúdo jornalístico, levando muitas pessoas a acreditarem em sua veracidade, as induzindo a compartilhar, mas vêm sendo recorrentemente utilizada para a criação e a circulação de fake news. Além de suspeitas de que o site tenha relação direta com o MBL.

Através de fragmentos coletados na internet, principalmente aqueles postados por grupos já citados, pequenos segmentos, em especial aqueles que não tiveram a oportunidade de ver a exposição, ficaram supondo do que ela se tratava, comentários recorrentes pautando o desrespeito à moral e aos valores da família tradicional brasileira, incitando que as obras se referiam à pornografia, além de crítica aos artistas por pautarem com frequência sobre sexo. Assim como a própria configuração do "museu queer", obras foram transformadas radicalmente indo contrário ao que se pretendiam ser, expondo um cenário de ignorância e intolerância quando temas como estes são expostos, isso se dá, pois muitas vezes a função da arte é justamente mostrar aquilo que não queremos ver.

Quando questionados, Kim Kataguiri, um dos líderes do grupo, afirmou à $\mathrm{BBC}$ News Brasil' ${ }^{6}$ que apesar de defenderem a liberdade de expressão, o protesto contra a mostra não defendeu censura e sim um boicote, devido ao mau uso do dinheiro público, tendo em vista, esta ser uma exposição promovida pelo financiamento indireto federal, através da Lei de Incentivo à Cultura ${ }^{7}$ - Lei Rouanet -, implicando em isenção fiscal à Receita Federal por parte da Instituição promotora e destinando a verba ao segmento cultural. Com isso, foi questionado pelo grupo a representatividade da mostra frente a maior parte dos valores da sociedade, valores estes conservadores e de uma sociedade moldada em padrões heteronormativos; além da presença de crianças na exposição que estavam sendo levadas por escolas e a falta de indicativo de idade mínima permitida e da presença de nudez em algumas obras. 
Apesar da campanha do MBL ter sido colocada como boicote, contribuiu sim com o ato de censura, devido ao cerceamento da liberdade de escolha e de expressão, tendo em vista que as pessoas foram impedidas de ver a exposição e tirar suas próprias conclusões, além de uma tentativa do grupo determinar o que poderia ou não ser visto e produzido pelo artista. Censura esta consolidada pelo Santander, ou seja, uma autocensura. O que resultou em protestos por parte de movimentos artísticos e sociais. Pois, apesar do Ministério Público Federal (MPF), em nota ${ }^{8}$, desmentir as acusações e negar crime de qualquer espécie, recomendando a reabertura imediata da Queermuseu, o banco Santander se negou a reabrir a mostra, assinando um termo de compromisso no qual se comprometia à realização de duas exposições sobre diversidade.

Em outubro de 2017 uma nova tentativa de exibir a exposição foi dada pelo Museu de Arte do Rio (MAR), que se mobilizou a reabrir a mostra na Praça Mauá, no Centro do Rio de Janeiro, fundamentada na importância de promover sua visibilidade para a população brasileira e internacional através do seu impacto e relevância artística. No entanto, partindo de uma iniciativa e decisão arbitrária, o prefeito da cidade, Marcelo Crivella (PSC), em uma manifestação pública, de forma caluniosa, reafirmando o processo difamatório já deflagrado e a acusação de incitação à pedofilia e zoofilia, por meio de um vídeo proibiu a remontagem no local.

O vídeo foi divulgado pelo prefeito em seu perfil no Facebook. O mesmo começa com pessoas dizendo que não "querem no Rio de Janeiro exposição de pedofilia e zoofilia", em seguida Crivella diz: "Tá vendo? É Por isso que aqui no Rio a gente não quer esta exposição" e em tom de deboche completa "Saiu no jornal que ia ser no MAR, só se for no fundo do mar porque no Museu de Arte do Rio, não". Caracterizando assim, um segundo ato de censura exercido pelo prefeito de uma das cidades brasileiras mais diversas do país tendo a mesma um caráter ainda mais grave.

A campanha para trazer Queermuseu ao Rio de Janeiro nasceu 
da indignação popular - manifestação e organização da classe artística - diante dessas decisões arbitrárias. Logo após o encerramento da mostra, a fotógrafa carioca Evelyne Marques Rodrigues, irritada com a postura reacionária de membros do MBL e do centro cultural que acatou uma postura retrógrada, resolveu intervir criando um abaixoassinado on-line na plataforma Change.org, a fim de que o Santander Cultural revisse seu posicionamento e reabrisse a mostra. A petição teve 71 mil apoiadores, dentre eles artistas, como o cantor Leoni, o cineasta Daniel Ribeiro, a atriz Vera Zimmermann, o diretor de TV e teatro Michel Melamed, a ex-ministra da Cultura Ana de Hollanda e o diretor de TV Michel Coeli. Ato que salienta que desde a sua censura, não faltaram sinais de apoio.

Com um país polarizado, o debate da Queermuseu reverberou também no âmbito político. Na Assembleia Legislativa do Espírito Santo o deputado Euclério Sampaio (PDT) lançou um projeto de lei que proibia exposições artísticas com nudez e referências a atos sexuais. De acordo com o Deputado, a atuação do poder público se fez necessária para evitar que as manifestações artísticas de cunho sexual fossem promovidas em espaços públicos. O projeto já havia sido aprovado na Assembleia em outubro de 2017, mas acabou sendo vetado pelo governo do Estado e no ano seguindo teve seu veto total por mais de $50 \%$ dos parlamentares.

Em âmbito federal, um projeto de lei do deputado Delegado Franscischini foi apresentado e tinha como intuito passar a criminalizar no Estatuto Da Criança e Do Adolescente (ECA) a exibição de órgãos genitais de adulto, criança ou adolescente para fins artísticos, fazendo referência ao Queermuseu e a performance do coreógrafo Wagner Schwartz no Museu de Arte Moderna (MAM) de São Paulo.

Apesar da polarização em torno da temática, observou-se uma aceitação positiva do tema por boa parte da opinião pública brasileira e da comunidade cultural, sendo lançada em janeiro de 2018 uma campanha de crowdfunding na internet, plataforma de financiamento 
coletivo, com meta de arrecadação de R $\$ 690.000$ (seiscentos e noventa mil) reais até 29 de março do mesmo ano, visando o retorno da mostra e do seu debate de forma autônoma. Por ser uma plataforma na qual você contribui naquilo que acredita e apoia, a campanha representou uma iniciativa democrática, aberta e coletiva, através de uma tomada de posição política que deve ser destacada dentro das instituições públicas brasileiras.

Juntamente ao crowdfunding, vale frisar outras ações, tais como, \#342 Artes $^{9}$ e a participação do cantor Caetano Veloso, que realizou em 15 de março um show beneficente, no qual o valor dos ingressos foi revertido para a campanha de financiamento coletivo, representando um impulso à mesma. Além da realização de um leilão beneficente, que ocorreu no mesmo evento, com obras doadas de 81 artistas, sendo que nem todos os artistas tinham vínculo com a exposição, mas entendem o impacto negativo para a sociedade que a censura ao Queermuseu representa.

O show intitulado Caetano Contra a Censura, ocorreu no Parque Lage, se tornando um ato político contra o fascismo e a intolerância que fechou a mostra, e em torno do assassinato da ativista e vereadora Marielle Franco e seu motorista Anderson Gomes, ocorrido no dia anterior. Mortos por este mesmo fascismo que vem matando mulheres, a comunidade LGBT, e os jovens periféricos do país.

A manifestação no show de Caetano Veloso se deu de forma a reafirmar a indignação com a atual conjuntura política brasileira, em que o país se viu em uma realidade de profundo obscurantismo, principalmente após o golpe contra a ex-presidenta Dilma Rousseff (PT) em 2016, onde grupos extremistas ascenderam. O colapso político do Brasil continuou se agravando com o governo Temer (MDB) que se voltava para um modelo mais centro-direita, defensor de pautas conservadoras, agravando a crise que se estendeu até o período eleitoral de 2018, resultando em revoltas populares de setores da sociedade trabalhadora e das classes mais baixas, geralmente mais 
prejudicadas nesses contextos.

A ascensão da extrema direita foi um dos fatores que ditou as eleições no país, através de um discurso conservador, preconceituoso e repressivo, um declínio das garantias fundamentais e um verdadeiro retrocesso nos âmbitos sociais e culturais. Elegeu-se um presidente misógino, preconceituoso e ignorante, de forma a manifestar e aumentar casos de repressão contra grupos sociais minoritários, que historicamente sofrem com a violência, como LGBTS, negros, índios e periféricos, por parte daqueles que se identificam com esta figura e sendo acobertada pela mesma, Com isso, a necessidade urgente de reflexão para construir um país com justiça social e igualdade para todos.

Estas ações levaram à frente o movimento e a necessidade de reabertura da mostra para a sociedade brasileira. Através da campanha, até o dia 26 de março foram arrecadados $\mathrm{R} \$ 724$ mil de 1.230 apoiadores, sendo o maior crowdfunding cultural já realizado no Brasil, conforme o curador Gaudêncio Fidelis. A campanha conseguiu chegar à marca de $\mathrm{R} \$ 1.081 .176,00$, no total, 1.724 pessoas colaboraram com a arrecadação, que foi encerrada no dia 29 de março de 2018, possibilitando a remontagem da exposição, que ocorreu na Escola de Artes Visuais (EAV) do Parque Lage, no Rio de Janeiro. Com o dinheiro arrecadado pela campanha crowdfunding, foram realizadas reformas nas Cavalariças do Parque - espaço de realização de exposição - possibilitando que a mostra fosse remontada para a população.

Idealizada pelo Diretor-Presidente da Instituição - Escola de Artes Visuais do Parque Lage - Fabio Szwarcwald, juntamente ao curador Gaudêncio, a Queermuseu teve sua reinauguração dia 18 de agosto de 2018 e ficou aberta ao público até 16 de setembro, visando manter o compromisso de resistência que a escola carrega consigo, se posicionando como um espaço livre para debates, em favor da liberdade de expressão, contra censura e de convivência empática. De acordo com Fabio Szwarcwald10, a reabertura da exposição 
caracterizou um ato político contra a censura e o posicionamento em favor da liberdade de expressão, sendo a EAV o centro catalisador de apoio dos mais diversos agentes de um amplo arco de membros da sociedade.

A escola realizou inúmeras atividades, como eventos multidisciplinares, até mesmo no período que antecedeu a abertura da mostra, contando também com uma plataforma de debates que contribuíram institucionalmente, antes e durante a exposição, além de ter visitas guiadas com ativistas de movimentos LGBTQI+, tendo em vista o comprometimento da escola com a diversidade e o respeito às demandas da sociedade, associado a um programa educativo. A equipe de mediadores era formada por 33 pessoas de diversas orientações sexuais e identidades de gênero, agentes fundamentais que contribuíram com os debates, trazendo novas perspectivas através de relatos diversos. Diferente de outras instituições, a EAV se colocou à frente, reforçando seu compromisso com a resistência, marco no contexto artístico brasileiro de ensino da arte.

\section{Representação}

$\mathrm{O}$ conceito de representação e as instituições representativas começaram a surgir na Idade Média, mas somente no século XIX nasceu a ideia moderna de representação, ligando seu conceito a um agente que agiria por outro, e as instituições à democracia. Diversos acontecimentos e reivindicações transformaram a realidade prática em torno do termo. Mas é Hannah Pitkin que apresenta em seu livro "O conceito de representação" publicado em 1967, a tipologia moderna de representação política que utilizamos. Baseada na obra "O Leviatã" do filósofo inglês do século XVII, Thomas Hobbes, desenvolve o argumento que através de um mútuo contrato indivíduos separados se tornam um corpo único, com isso, para além de ser considerado um teórico do contrato social também é um teórico da representação, pois é neste corpo político, que está a figura do representante, apesar da sua 
definição para o soberano ir contrário à própria definição de representante, com ressalvas, visto que o representante é alguém que assume a responsabilidade em nome dos quais ele age e não somente um ato de autorização de forma ilimitada que age sem consultar os interesses do povo. Outras concepções de representação possíveis e que vão em direções opostas foram pautadas a partir de críticas à teoria hobbesiana (CARDOSO; MARTINS, s/d). Em síntese, para Pitkin (1967) a representação torna presente o que está ausente.

Tendo em vista a impossibilidade de reunir todos os cidadãos para deliberar sobre diferentes interesses e pautas, a democracia busca por meio da representação, sendo este um mecanismo alternativo, efetivar o governo do povo. No entanto, é perceptível em regimes democráticos a super-representação de alguns segmentos enquanto outros grupos são excluídos. Grupos considerados minoritários, sejam de trabalhadores, população negra, indígenas e LGBTQI+, entre outros, são afastados desses espaços deliberacionistas seja pela dinâmica da exclusão social ou pelos filtros institucionais, que reproduzem as desigualdades sociais também nas esferas públicas e políticas. Considerando que estes segmentos que ocupam as instituições não representam a pluralidade de sujeitos, interesses e pensamentos, por serem basicamente homens, ricos, brancos e heterossexuais, observa-se a ineficiência destes sistemas políticos, sendo eles incapazes de representar seu povo e seus anseios, além de fomentar a descrença no funcionamento das instituições e na política como espaço de mediação de conflitos e conquistas de direitos (PEREIRA, 2017).

Em tempos obscurantistas, em meio a práticas higienistas, de censura à arte e de perseguição política à parlamentares ativistas nas instituições democráticas, a luta política tem se feito presente em diferentes espaços públicos, fora das instituições. A política das multidões queer representa essa descentralização, engajando-se na construção de uma militância mais interseccional, priorizando estratégias através de manifestações culturais, por entender que 
preconceitos nascem na cultura, utilizando-se de performances políticas nas ruas, manifestos, gritos de ordem, tendo em vista o uso do corpo como instrumento de discurso político. Mas apesar dos Movimentos lutarem por seus reconhecimentos, nota-se uma ausência dessas pessoas nos espaços das instituições representativas dificultando a própria representação política desses grupos, resultando em uma lacuna social.

De acordo com Cleyton Feitosa Pereira (2017), diversos fatores são atribuídos a essa ausência nas esferas de representação, tais como a exclusão social provinda pela escassez de recursos, as estruturas desiguais da sociedade e as diferentes formas de violência sofrida por eles que resulta em uma desmotivação a ambição política. Para além desta problemática, parafraseando Lousao, (2011), enquanto a modernidade pensa na representação baseada na autorização, as formas contemporâneas se baseiam na multiplicidade e na afinidade criada em torno de temas e causas, indo de encontro às teorias e objetivos queer levantados.

\section{Considerações finais}

O golpe contra a estrutura constitucional-democrática brasileira consistiu em deslegitimar o campo político e a dignidade da luta política, dando espaço a uma demanda moralizadora, em que pessoas foram iludidas pela promessa de limpeza moral de um país, supostamente sujo pelas forças democráticas, e da corrupção que se estabeleceu dentro da mesma, além da saída da crise econômica. A democracia foi derrotada em 2016, com o golpe à ex-presidenta Dilma Rousseff (PT), mas, na sociedade, ela vem sendo derrotada muito antes, o ataque e a desmoralização à democracia abriram o caminho da permissividade para violações inimagináveis e esse fracasso foi condição fundamental para a censura, a perseguição às minorias, o ódio político e a privação das expressões democráticas. Mas é válido ressaltar que essas construções não se consolidam de uma hora para 
outra, são gerações de transmissões de preconceitos, hostilidades e medo para que se perpetuem.

Apesar da aparente inclusão decorrente da visibilidade das mulheres, indivíduos LGBTQI+, afrodescendentes e indígenas que passaram a ganhar mais espaço e protagonismo nessas manifestações, decorrente de políticas afirmativas de inclusão, visibilidade e representatividade desses sujeitos e, consecutivamente, de terem entrado em pauta na sociedade discussões referente a temáticas pertinentes a esses sujeitos, assistimos ao crescente ataque a produções midiáticas, artísticas e culturais que apresentem esse viés identitário. Isso se deve a um aceitamento dessa visibilidade deste que estes sujeitos respondam aos limites socioculturais heteronormativos, pois diferente disso despertam controvérsia, repulsa e ataques.

Mesmo que perseguição e censura ao Queermuseu pareça um episódio isolado, mostra-se como um sintoma da desagregação perceptiva acarretada pela degeneração da democracia, representando a força da destruição em curso no país. É a censura a uma expressão artística no âmbito da diversidade de gênero, operada por um banco em resposta a grupos radicais de extrema direita, e pelo neopentecostalismo e catolicismo, tendo um caráter muito mais grave, exatamente pelo seu cunho moralista e ecumênico. Características que ferem brutalmente a neutralidade do Estado e a sua laicidade. E apesar de não ser a primeira vez que esse tipo de censura acontece com relação a obras de arte, esse episódio diz muito do nosso contexto atual. Estamos passando pelo empobrecimento das diversidades e dos debates que constroem de fato uma democracia, através da polarização política e superficialidade de debates a partir do crescimento de uma onda conservadora no país, que tenta encolher nossa democracia. No Brasil o ódio se tornou uma categoria política, transportada do domínio mais opressor da sociedade, que, vem reagindo com o uso da força como vetor de sua legitimação. $\mathrm{O}$ ataque à diversidade de gênero é, em qualquer contexto autoritário, paradigmático e, em larga medida, uma consequência lógica do fechamento democrático. 
Contudo, em tempos obscuros como os nossos, pouco afeitos ao discurso contrastante, e em que debates são silenciados através de um forçoso convencimento do outro através de coação, sabotagens, censuras e um discursos fundamentalistas que sustenta a não aceitação da diferença, pautados principalmente por grupos religiosos radicais que falam em nome da família e dos bons costumes, se posicionando seja contra o aborto ou "ideologia" de gênero e sustentado por uma leitura literal do religioso, acolhida por representações poderosas presentes em Câmaras Legislativas do Brasil, e através da Bancada Cristã no Congresso Nacional, em que discussões que problematizam o sexismo, a misoginia e as fobias (homo, bi e trans) têm sido barradas. Esses episódios devem despertar nossa atenção para o potencial, ainda pouco explorado, dessas plataformas queer para a formação e para a descolonização do saber e do olhar, fazendo-se necessário um desvio queerizado do pensamento, tendo em vista suas ações e epistemologias polissêmicas.

Se tomarmos a Queermuseu como modelo, por ter redimensionado a relação operacional dos modelos tradicionais e eurocêntricos das instituições - museus - e nossa relação com os objetos dessa exposição, quebrando assim o vício normativo existente em diversos setores, como nos de produção de conhecimento acadêmico. E por frequentemente se interessar pelas políticas de representação e subalternidade, abre-se a possibilidade de utilizarmos esse desvio em outros segmentos da sociedade, para além, pensarmos em novas políticas de representação, através de instituições do desvio antinormativo, rompendo metodologias e formulações de bases fundamentalistas pautadas na lógica binária, dicotômica e misógina.

O pensamento queer nos ajuda a desenvolver formas de pensar e refletir as estruturas de representação, se comprometendo com o desafio de desenvolver alternativas éticas e não excludentes dos indivíduos, podendo colaborar para novos modos de acolhimento que transcendam o fundamentalismos, seja no âmbito social, político ou cultural. Todavia, pensar no sujeito queer, marginalizado, contribui 
para nos sensibilizar diante uma vida em que o diferente seja acolhido na diferença porque essa diferença também se encontra em mim, ou seja, é um desafio intelectual e político que pode contribuir para desestruturar o status quo, e de forma anti-fundacionista repensar nossa condição atual e ideais em que se assentam o valor e o saber das sociedades contemporâneas.

A arte e a cultura são peças-chave que devemos utilizar de forma a potencializar o reconhecimento do outro a fim de buscar uma visão coletiva de pertencimento, para então desafiar e questionar as tradicionais estruturas institucionais, desconstruir discursos opressores e rearticular normas. É preciso se fazer presente nas arenas decisórias, levantar debates ligados a grupos minoritários, resistir e não recuar, e projetos culturais tendem a provocar a crítica reflexiva necessária nestes momentos. A "Queermuseu: cartografias da diferença na arte brasileira" se colocou como um desses projetos, oportunizando o diálogo e o debate sobre a diversidade na arte brasileira e na cultura contemporânea, através das inúmeras questões de gênero levantadas que ultrapassam os aspectos desta contemporaneidade. Para além fica o convite para pensarmos em novas políticas de representação através da ótica queer, um convite a dialogar com diversidade, através da multiplicidade de possibilidades, realidades e demandas.

\section{Referências}

BUTLER, Judith. A vida psíquica do poder. Teorias da sujeição. Tradução de Rogério Bettoni, 1. ed. Belo Horizonte: Autêntica Editora, 2017 (Filô).

BUTLER, Judith. Problemas de Gênero, Feminismo e subversão da identidade. Tradução de Renato Aguiar. 15. ed. Rio de Janeiro: Civilização Brasileira, 2017.

CARDOSO, Fernando Henrique; MARTINS, Carlos Estevam. O conceito de representação. 
CARRARA, Sergio; SIMOES, Julio Assis. Sexualidade, cultura e política: a trajetória da identidade homossexual masculina na antropologia brasileira. Cadernos Pagu, .n.28, p. 65-99, jan./jun. 2007.

CASTRO, Mary C; ABRAMOVAY, Miriam; SILVA, Lorena Bernadete. Juventude e sexualidades, UNESCO, Brasil, 2004. Capitulo 6. Ressignificando sexualidades por violências, preconceitos e discriminações.

CRUZ, Cecilia Mori. A Beleza Profana: Uma integração da abjeção na arte. Programa de Pós-graduação em Arte. Universidade de Brasília, 2007.

DIDI-HUBERMAN, Georges. De semelhança a semelhança. Tradução de Maria José Werner Salles. Alea, v .13, n .1 Rio de Janeiro Jan./June 2011.

DIDI-HUBERMAN, Georges. O Que Vemos, O Que Nos Olha. Tradução de Paulo Neves. São Paulo: Editora 34, 1998. 264 p. Coleção TRANS.

FEITOSA, Cleyton. Barreiras à ambição e à participação da população LGBT no Brasil. Revista Ártemis, v. XXIV, n. 1, p- 120-131, jul./dez. 2017.

FOCAULT, Michel. Historia da Sexualidade I: A vontade do saber, tradução de Maria Thereza da Costa Albuquerque e J.A. Guilhon Albuquerrque. Rio de Janeiro, edições Graal, 1988.

KRISTEVA, Julia. Powers of Horror: an essay on abjection. Nova Iorque: Columbia University Press, 1982.

LOURENÇO, Daniel. Queer na primeira pessoa: notas para uma enunciação localizadora. Universidade de Lisboa/Lisboa, Portugal. Revista Empiricus. 2017.

LOUSAO, Antoine. Da representação na política à representação política: um conceito frente à dupla exigência de legitimidade e pluralidade. Cadernos de Ética e Filosofia Política 18, 1, p. 47-71, 2011.

MARINHO, Cristiane Maria; VERAS, Elias Ferreira. Michel Foucault e a Teoria Queer. Revista Bagoas (UFRN) - Estudos gays: gêneros e sexualidades, n. 16, p. 21-28, 2017.

MISKOLCI, Richard. A teoria Queer e a sociologia: o desafio de uma analítica da normalização. Revista Sociologias, Porto Alegre, ano 11, n. 
21, p. 150-182, jan./jun. 2009.

NASIO, J-D. 9 Lições sobre Arte e Psicanálise. Rio de Janeiro: Zahar, 2017.

PHILLIPS, Anne. De uma política de ideias a uma política de representação. Revista Estudos Feministas, v. 9, n. 1,p. 268-289, 2001.

PRECIDADO, Beatriz. Multidões Queer: notas para uma política dos "anormais" (Universidade de Paris). Revista Estudos Feministas, Florianópolis, n. 19, v.1, p. 11-20, 2011.

Reproduzido de Pitkin, H. F. Representation, 1996. Política e Sociedade, v.2 (s/d).

RODRIGUES, Paulo Roberto Grangeiro. Influência social, minorias ativas e desenvolvimento moral: ensaio teórico sobre a representatividade política brasileira. Psicologia e Sociedade, 30, 2018.

SALES, Adriana; LOPES, Herbert Proença; PERES, Wiliam Siqueira. Despatologizando as travestilidades e transexualidades: saúde mental e direito. Revista Periódicus, n. 5, v. 1, p. 56-72, 2016.

SCOTT, Joan. Gênero, uma categoria útil de análise. Revista Educação e Realidade, v .20, n. 2, 1995.

YOUNG, Iris Marion. Representação política, identidades e minorias. Revista Lua Nova, São Paulo, n. 67, p.139-190, 2006. 